\title{
Managing biological invasions: charting courses to desirable futures in the Cape Floristic Region
}

\author{
Núria Roura-Pascual • David M. Richardson · \\ R. Arthur Chapman · Tanja Hichert • \\ Rainer M. Krug
}

Received: 21 September 2009/Accepted: 3 June 2010/Published online: 18 June 2010

(C) Springer-Verlag 2010

\begin{abstract}
Invasive species alter the functioning of natural ecosystems, creating "novel ecosystems" comprising species occurring in combinations with no analogs within a given biome. This poses major challenges for managers who cannot rely exclusively on previous experiences. Multiple factors that drive invasion and which interact in complex ways demand innovative management approaches. We show the utility of scenario planning in considering options for management in a region with substantial
\end{abstract}

Electronic supplementary material The online version of this article (doi:10.1007/s10113-010-0133-5) contains supplementary material, which is available to authorized users.

N. Roura-Pascual · D. M. Richardson · R. M. Krug

Centre for Invasion Biology, Department of Botany \& Zoology,

Stellenbosch University, Private Bag X1, Matieland 7602,

South Africa

e-mail: rich@sun.ac.za

R. M. Krug

e-mail: Rainer@krugs.de

R. Arthur Chapman

CSIR Natural Resources and the Environment,

P.O. Box 320, Stellenbosch 7599, South Africa

e-mail: arthur@oneworldgroup.co.za

R. Arthur Chapman

OneWorld Sustainable Investments,

PO Box 8359, Roggebaai 8012, South Africa

T. Hichert

Institute for Futures Research, Stellenbosch University,

P.O. Box 2010, Bellville 7535, South Africa

e-mail: Tanja@hichert.co.za

N. Roura-Pascual $(\square)$

Àrea de Biodiversitat, Centre Tecnològic Forestal de Catalunya, Ctra. de St. Llorenç de Morunys km 2, 25280 Solsona, Catalonia e-mail: nrourapascual@gmail.com problems with invasive alien plants: South Africa's Cape Floristic Region. The approach allows us to identify the driving forces that shape the status and trajectories of major woody invasive plants and to identify sensible strategies by considering a set of scenarios based on the main uncertainties that encapsulate the linkages between the various components of the management of biological invasions. Attitudes of landowners and management capacity are shown to be the crucial uncertainties influencing the spread of major invasive species; axes based on these factors define our scenarios. Mapping current management projects onto scenario axes highlighted key differences among areas. These insights can assist in directing particular management units toward more desirable futures. Our study highlights the need to link social, political and legal constraints with ecological processes to assure the effectiveness of management operations in controlling biological invasions.

Keywords Biological invasions - Cape Floristic Region . Fynbos - Invasive alien plant species .

Management strategies $\cdot$ Scenario planning

\section{Introduction}

The movement of humans and goods around the globe is occurring at rates unprecedented in human history. This has disrupted the biotic equilibrium maintained over eons by geographic and climatic barriers and has transported organisms beyond their natural ranges. Some of these introduced species escape the regulating influences of their key natural enemies and become invasive (i.e., establish, proliferate and spread) in their new ranges (Mack et al. 2000). In many ecosystems, invasive alien species can, if 
left to spread unchecked, transform the structure and functioning of ecosystems, leading to substantial losses of ecosystems services and demanding considerable expenditure on attempts to prevent their expansion and the incursion of new invaders (Hulme 2006).

Increasing attention is being given to developing pragmatic approaches for managing "novel" or "emerging ecosystems"- those comprising combinations of species with no historical analog and where changed conditions preclude a return to some historical state (Hobbs et al. 2006). Management of these ecosystems is characterized by high levels of uncertainty. There are no tried and tested management methods for dealing with these new environmental conditions, and every management intervention is an experiment. This uncertainty is defined by the limited knowledge of the multiple factors driving the invasions, and these are often not apparent at first observation of the problem (e.g., see Le Maitre et al. 2004). Consequently, management intervention tends to focus on control activities and not on the predisposers that lead to constant invasion pressure. Integrated and flexible frameworks considering these multiple drivers and their future outcomes are required to provide adequate solutions (Seastedt et al. 2008).

Under this new management paradigm, scenario planning is an appropriate technique for shedding light on the multiple complexities and the high degree of uncertainty of how and environment is predisposed to invasion, the drivers and outcomes in biological invasions that confront managers seeking to establish effective long-term strategies (Peterson et al. 2003). Several studies have considered scenario planning as an approach to deal with uncertainties in future environmental conditions and guide conservation plans (Berkhout et al. 2002; Bohensky et al. 2006; Odada et al. 2009; Voinov et al. 2004), but few have use this technique to explicitly guide management options for controlling biological invasions (Chapman et al. 2001; Le Maitre et al. 2004). This paper applies scenario development methods in a novel way to guide management of biological invasions, using South Africa's Cape Floristic Region (CFR) as a test case (Fig. 1).

The CFR, one of the five regions of the world with a mediterranean-type climate, is one of the planet's major biodiversity hot spots, and hosts an incredible biological richness and high levels of endemism (Cowling et al. 2003). The natural beauty of the combination of this unique vegetation and the landscape is of great financial and social value to people in the region (Higgins et al. 1997). Large areas of natural fynbos vegetation are, however, invaded by trees and shrubs, especially species of Acacia, Eucalyptus, Hakea and Pinus. These invasions have led to reduced runoff from catchments in the water-scarce region, altered fire regimes and promoted the suppression of the indigenous vegetation (Biggs et al. 2008; Richardson et al. 1992). The implicit and explicit costs of these invasions for the South African economy are significant (Turpie et al. 2003), and substantial management interventions have been implemented to address the escalating threats they pose to sustainable conservation of biodiversity and utilization of ecosystem services (Richardson et al. 2004).

The Working for Water programme is the largest initiative focussing on controlling invasive alien plants (IAPs) throughout South Africa (and one of the largest conservation/restoration programs in the world). Although it has been widely lauded as an environmental management program (e.g., Hobbs 2004), it is primarily a povertyalleviation initiative. Until now, the dual aims of the program (poverty alleviation and conservation) have usually been accommodated (Macdonald 2004), but changes in the political landscape could easily disrupt the program, making the sustainability of the initiative tenuous. Despite considerable progress in controlling invasions, especially over the past two decades, the problem in the CFR is immense (van Wilgen 2004). Inherent complexities generated by the interplay of species attributes and environmental features, together with logistical complexities as a result of socio-political factors, thwart the effectiveness of the control programs and impede the implementation of a uniform strategy for the whole CFR (Roura-Pascual et al. 2009). The success of management depends on interconnected and dynamic factors of many types that vary considerably across the region, and also on the sustainability of control actions over extended periods of time (i.e., years, decades). A framework for considering the drivers toward, and implications of, plausible futures relating to biological invasion in the CFR could assist in designing strategies that are optimally flexible and which are best suited for ensuring success of current control actions over time. Managers and planners need to understand the complex ways in which these factors affect control programs, but allowance must be made for future events that could radically alter trajectories (Peterson et al. 2003).

Our aim is thus to construct plausible futures for invasions of plant species in the genera Acacia, Eucalyptus, Hakea and Pinus in the CFR at a scale meaningful for management (regional scale at a project level; Fig. 1). We started by identifying uncertainties associated with the most influential drivers and those having a major impact on the environment (in terms of spread of invasive plant species). This allowed us to derive a set of scenarios for managing these invasive species. By mapping the current position of different clearing projects with respect to the scenarios, we sought insights regarding the most appropriate management approaches and explored options for arriving at preferred futures through adaptation of management approaches. We suggest that very significant 
Fig. 1 Illustration of the spread of invasive alien plants in the Cape Floristic Region at the southern tip of South Africa (indicated in lighter gray) in relation to South African provinces, and location of selected management projects (yellow patches) of the Working for Water programme to reduce the extent of invasive species. Photographs show a sample of management units discussed in the text and illustrate the essence of various management contexts in the region



IAPs photos

(by D.M. Richardson)

a Table Mountain

b Cederberg

c Citrusdal

d Hermanus

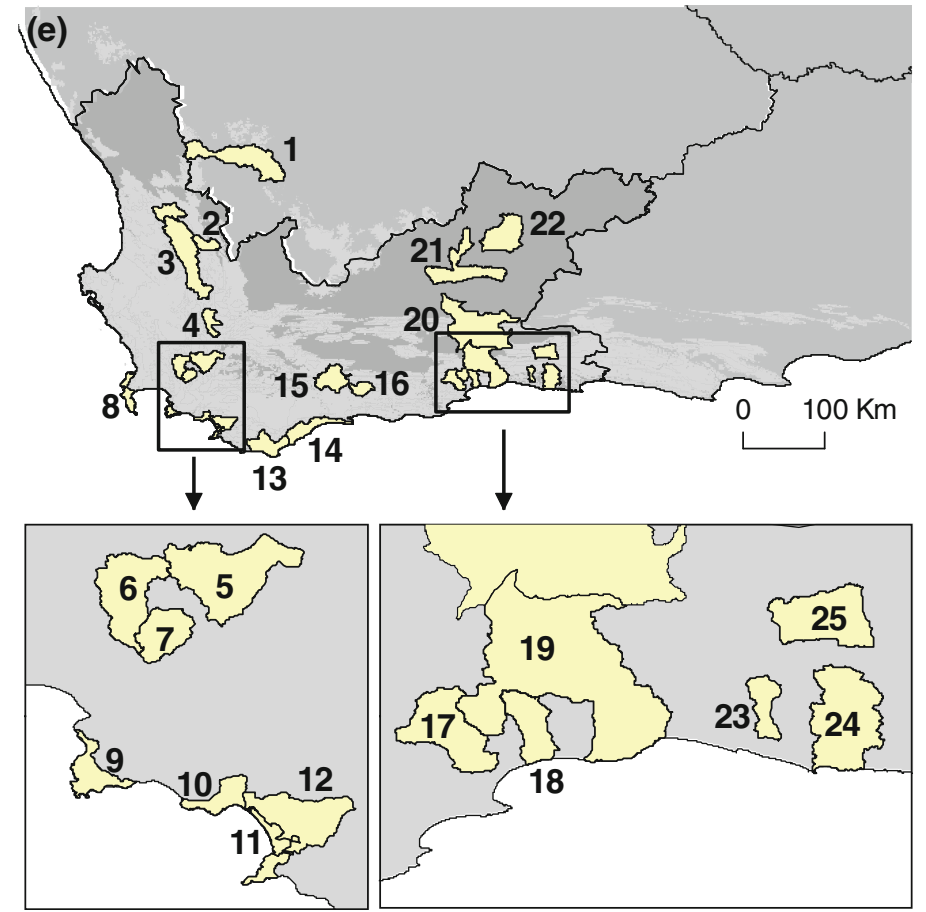

\section{Clearing projects}

1 Calvinia

2 Cederberg

3 Citrusdal

4 Ceres

5 Worcester

6 Berg River

7 Assegaaibos

8 Table Mountain

9 Protea

10 Hermanus

11 Kleinriver

12 Walker Bay

13 Agulhas

14 De Hoop

15 Buffeljags

16 Duivenhoks

17 Brandwacht

18 Groot Brak

19 Outeniqua

20 Swartberg

21 Leeu Gamka

22 Beaufort West

23 Karatara

24 Knysna

25 Uniondale impacts on the invasion process can be made by influencing the driving forces or by adapting management action appropriately.

\section{Methods}

Scenario planning is a method for learning about the future by understanding the multiple driving forces whose future trends are either certain or uncertain (Schwartz 1991). It is a group process, which encourages knowledge exchange and development of a deeper understanding of the issues under discussion. The diversity of the assembled expertise allows the widest possible range of drivers to be recognized. The goals are to identify the multiple drivers of change and to craft a number of diverging "stories" by extrapolating uncertain but influential driving forces. As an example, human population growth in an area is a crucial driver of change and can be predicted with a high level of confidence. Socio-economic developments are also crucial drivers of change, but their trajectories are very difficult to predict. While keeping in mind the impacts of certain driving forces that can be accurately predicted, it is more important to concentrate on the possible impacts of those influential but uncertain drivers of change that could follow different trajectories, each of with different implications. These stories increase our knowledge of the topic, but also widening our perception (and that of policy makers) of possible future outcomes and events that may not be immediately obvious (Korte and Chermack 2007).

We thus chose to use the scenario planning method because it is proactive and tries to anticipate the possibility 
of future events, allowing pre-emption, which may be more cost effective and efficient than adaptive management processes which are reactive and inherently contain lags through the management feedback systems (see for example Apitz (2008)). Adaptive management brings a measure of inefficiency to the invasion management process, which could be improved by anticipating the full suite of possible future events and the implications of management interventions. This anticipation of the future is already widely applied in disaster management because of the inherent advantages of proactive management, even though risks cannot be assessed exactly (Weichselgartner 2001)

We used the approach outlined by Wilkenson (1995) to develop scenarios for conditions pertaining to the status and dynamics of IAPs in the CFR. The procedure was facilitated by an expert on strategic conversation (Tanja Hichert) to avoid particular points of view from dominating discussion and to ensure that the process was applied appropriately. The essential steps were:

1. Identification of the focal issue around which to build the scenarios.

2. Identification of the certain driving forces (or certainties) at work that set the pattern of events and make things happen, or predispose an environment to certain events. The facilitator of the participatory process guided the team through a brainstorming process to identify these main drivers based on the experience and knowledge of the participants. At the end of the process, ideas were reformulated into coherent sentences, and cross-checking ensured that all relevant issues had been captured.

3. Based on the results of the brainstorming process, the next step was to identify the main uncertainties related to the question under discussion. Uncertainties are not related to probabilities, but to predictability (i.e., how much do you know about them to describe their current state and predict future outcomes).

4. Evaluation of the impact and the level of unpredictability of these uncertainties to identify those that have the greatest impact and the highest degree of uncertainty (i.e., those that we have the least knowledge about), as well as their linkages and synergies. All the uncertainties were plotted on an impact-uncertainty chart using expert consensus.

5. The key uncertainties were rephrased and expressed as opposite extremes to form the axes of the scenario matrix, which is a graphical representation of the four scenarios based on these key uncertainties. We then plotted the position of various certain driving forces (identified in step 2) and the directions in which they push to different plausible futures. This procedure allowed us to identify the particularities of each scenario and synthesize the information in a set of stories that encapsulate important aspects of the future.

We developed the overall analysis during a meeting in Stellenbosch in October 2008. Final results (i.e., identification of certainties and uncertainties, and selection of scenario axes) were amended and validated in several follow-up meetings in October through December 2008 with experts in the field, both researchers with expertise in the ecology and management of IAPs and managers charged with controlling operations at different levels (see Acknowledgements for a list of key contributors).

Once the scenarios were built, we asked managers to map different management units (i.e., area defined at a regional scale subject to a clearing project, Fig. 1e) and their probable future outcomes based on current management practices onto the scenarios matrix. The objective was to make sense of their current state and identify phenomena characteristic of each scenario. Additionally, to identify trends in current clearing operations, we searched for differences among areas pertaining to each scenario in relation to funding available for clearing operations and land-use practices, including the percentage of urban areas, forestry plantations and agriculture activities (extracted from the national land-cover database; Fairbanks et al. 2000). The percentage of urban areas was used as surrogate of remoteness, which relates to the public perception of the need to control IAPs and the increased transactional costs during clearing operations. On the other hand, the percentage of forestry plantations and agricultural activities in each area signaled propensity for re-invasion or sources of propagule pressure. Differences between scenarios were visualized by means of box plots, and the main tendencies plotted using radial graphs.

\section{Results}

Identification of certainties and uncertainties

Our finding regarding the focal issue around which scenarios were built was: "What will be the features of management strategies for invasive alien plants in the Cape Floristic Region in the 50 years from now?" The answer to this question is not straightforward, since multiple factors drive invasions and affect the capacity of managers to influence them. Our expert group identified 29 certainties that are influential in the management of IAPs at regional scales in the CFR (Online Resource 1), and seven uncertainties that make future management actions unpredictable (Online Resource 2). These were classified into seven broad categories: political forces, social trends, economic 
realities, technological advances, regulatory environment, environment interface and management constraints.

Most certain drivers have already been identified as relevant by managers working on IAPs or ecological studies, especially those related to the characteristics of the environmental interface (Online Resource 1). For instance, $\mathrm{Nel}$ et al. (2004) used the characteristics of invasive alien plants and their ranges to rank species for control and Roura-Pascual et al. (2009) prioritized areas considering the influence of ecological factors and disturbance regimes, such as the opportunity that wildfires created to remove alien plants at a relatively low cost (van Wilgen et al. 1992). Nevertheless, few socio-political factors have been explicitly considered in control programs due to their intangible and unpredictable nature. This is also reflected in the seven uncertainties, which can be summarized as constancy of funding and political will supporting management actions, capacity of institutional and private structures required to apply the control effort and compliance to legislation (Online Resource 2).

\section{Scenario building}

From the seven uncertainties (Online Resource 2), we identified the most influential ones after plotting them in an impact-uncertainty chart based on expert agreement (Fig. 2). These were landowner commitment (to removal activities), funding of invader control activities, political will and commitment to support control activities and clearing effectiveness (Fig. 2, gray circle). Because the last

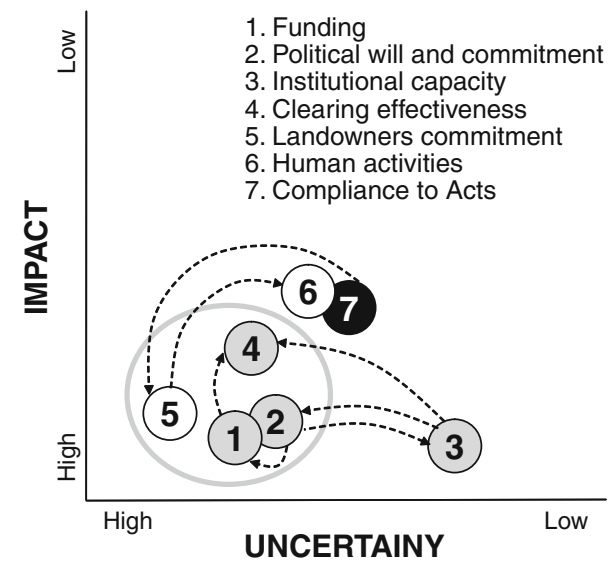

Fir $\rightleftharpoons$ chematic representation of the impact and degree of un $\overline{\bar{\nu}}$ hty associated with uncertainties (detailed in Online Resource 2) in the management of invasive alien plants in South Africa's Cape Floristic Region. The impact and degrees of uncertainty were derived in a workshop with experts. Dashed lines indicate influences on, or relationships between different uncertainties, and the shading of the circles denotes the type of uncertainty: management constraints (gray), social trends (white) or regulatory environment (black). The gray circle identified the key uncertainties used to construct the scenario axes three key uncertainties are linked under the management context, we built our scenarios around two main axes which we named: "landowners' attitude" and "management capacity" (Fig. 3). The axis named landowners' attitude shows a gradient from areas where human activities do not favor the spread of IAPs (hereafter "Responsible activities"), because landowners undertake appropriate measures to limit their spread into neighboring areas, to areas where the extent of IAPs on the environment is completely out of control-IAPs proliferate and management attempts are ineffective ("Free-riders phenomenon"; Fig. 3, vertical axis). The axis named management capacity is a composite of various factors and reflects the capacity of agencies tasked with clearing operations to allocate resources appropriately and to act effectively to control the extent of IAPs. "High capacity" corresponds to areas with the appropriate level of resources (both financial and human resources) to conduct effective clearing operations on the ground, and areas with limited resources but adequate capacity to maximize the available resources; contrarily, "Low capacity" refers to areas where either available resources are insufficient or the capacity for planning clearing operations is lacking (Fig. 3, horizontal axis).

Based on these two axes that encapsulate the most relevant uncertainties influencing the effectiveness of control operations, we identified four scenarios which we named: (1) Treading Water, (2) Meltdown, (3) Losing ground and (4) Maintain the gains (Fig. 3a). "Maintain the gains" was identified as the preferred future. The certain drivers (listed in Online Resource 1 and latter plotted in the scenarios axis to evaluate their influence) favoring this scenario are: landowner cooperation, innovative and flexible adaptation, availability of reliable data and developments in biocontrol technology. Contrarily, human activities (i.e., forestry and agriculture), increasing urbanization, degradation of land and need to satisfy employment needs have an antagonistic effect and push the management of IAPs in the opposite direction-toward the "Meltdown" scenario. "Treading Water" and "Losing ground" would be in a middle situation between the two aforementioned scenarios, the first one being constrained by the reduced capacity of management agencies in charge of the control operations and the latter by the overwhelming impact of human activities on the spread of IAPs (Fig. 3a) (see Box 1 for a more detailed description of the scenarios).

Localization of various management units

To exemplify the consequences of both human activities and management capacity on the environment, managers on IAPs in the CFR mapped real management units on the scenarios' matrix (Fig. 3b). In so doing we could elucidate 


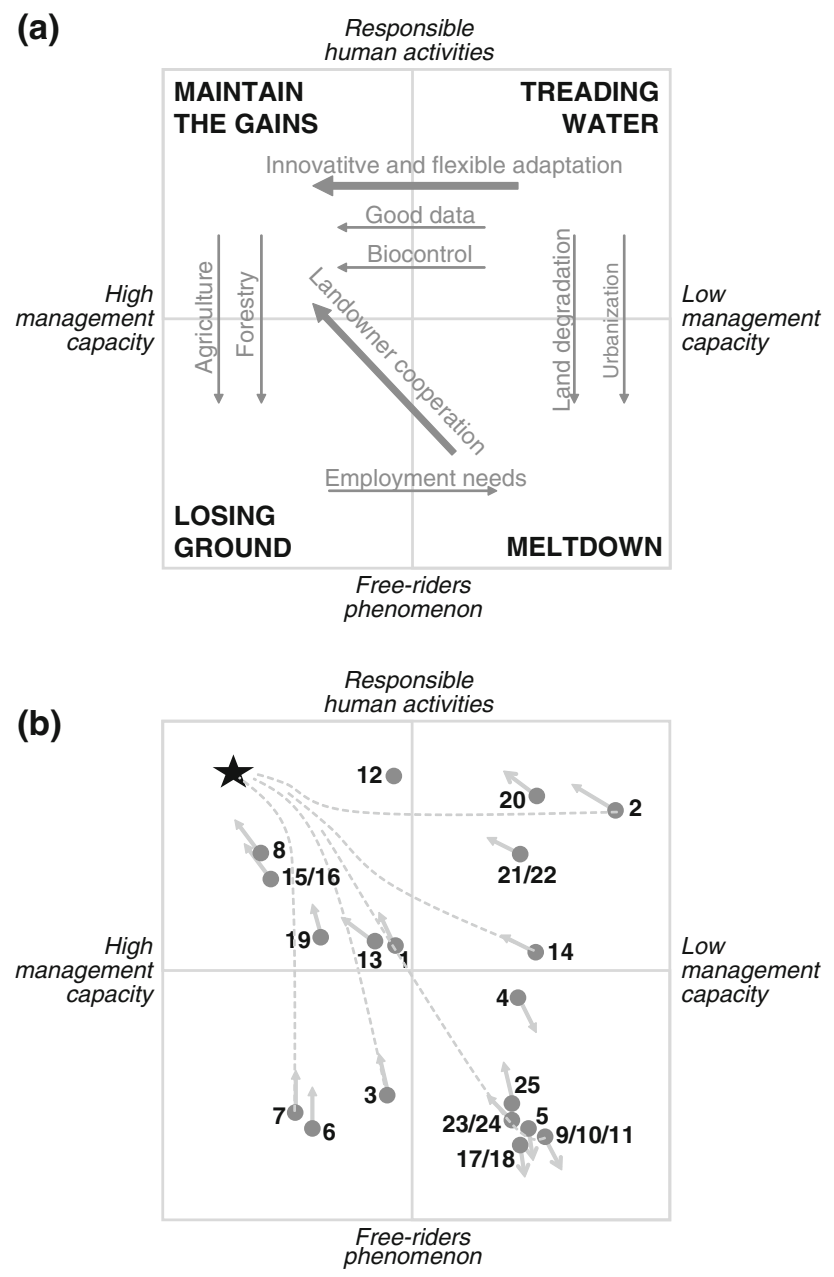

Fig. 3 Plausible scenarios for the management of invasive alien plants in the Cape Floristic Region based on two of the most uncertain and influential factors (human activities and management capacity) (a), and localization of some management projects in relation to these two factors (b). The arrows in a are not linked to a specific scenario and indicate the direction in which different certainties (listed in Online Resource 1) push toward certain scenarios; in $\mathbf{b}$, they show the direction in which each management unit (numbers refer to projects listed in Fig. 1) is tending relative to its current position. The dashed lines in $\mathbf{b}$ indicate the trajectory to follow to arrive to "Maintain the gains" from some of the sampled projects (refereed in Box 1)

differences among management units and characterize the different management scenarios in more detail by taking into consideration the characteristics of the areas included in each one of these. We did not find significant differences in the variables considered in the analysis between scenarios (Online Resource 3), probably because of the reduced sample size and the multiple factors determining the status of biological invasions. Nevertheless, the following tendencies were observed: (1) high percentage of forest plantations in scenarios "Meltdown" and "Losing ground", but a high percentage of agricultural land is associated only with the latter; (2) more remote areas (i.e., with lower percentage of urban areas) are more likely to fall within the "Treading water" scenario; (3) funding for alien clearing is surprisingly high in "Meltdown" scenario, but low in "Treading water" scenario, which has the lowest budget of the four considered scenarios (Fig. 4). These analyses allowed us to identify strategies that could potentially steer the units toward more preferred conditions, depending on their relative position on the scenario matrix (trajectories shown in Fig. 3b and described in Box 1).

\section{Discussion}

The influx of alien species and the trajectory toward escalating invasions was initiated long ago, but there are options for slowing the increase and reducing the magnitude of impacts (Hulme 2003). Long-term management of biological invasions must, however, deal more effectively with multiple future uncertainties associated with changes in the environment and socio-political environment (Lodge et al. 2006). Our study shows the utility of scenario planning as an appropriate framework for guiding management of "novel ecosystems". Scenario planning allowed us to make greater sense of the complexities and uncertainties implicit in the management of invasive alien plants in the Cape Floristic Region at the spatial scales (regional) used in decision-making. It enabled us to identify the main driving forces that shape the present status and the options for management of IAPs and to construct a set of scenarios grounded on the main uncertainties that encapsulate the linkages between the various components of the management of biological invasions. The essence of the information gathered during the process was already known by scientific and management experts on IAPs, but the procedure allowed us to formulate the information into a structured framework that facilitates its comprehension and public communication. It was also a useful tool for developing guidelines for directing particular management units toward more desirable futures.

The ideal management scenario for reducing the consequences of IAPs on the environment and ecosystem services is the one we have termed "Maintain the gains", where the levels of IAPs are contained and the capacity of agencies in charge of control operations allows effective early detection and rapid response to deal with invasive species before they spread over large areas and cause major damage (Box 1). Such efficient management is the result of political commitment to protect the environment and the capacity of management agencies to allocate resources appropriately and assure the effectiveness of the clearing operations on the ground and their maintenance over time (van Wilgen et al. 1992). However, few areas in the Cape Floristic Region currently experience such conditions. The configuration of human activities and management 
Box 1 Description of plausible scenarios for conditions relating to the status of invasive alien plants (IAPs) and management approaches for addressing problems associated with invasions in South Africa's Cape Floristic Region (CFR)

Treading water: While human activities have little effect in promoting the spread of IAPs, the capacity of agencies in charge of clearing operations is insufficient to reduce the extent of the invaded patches. If managers are unable to allocate their resources appropriately and control IAPs now that they are still at an earlier stage of the invasion, these areas will face a Meltdown scenario in the future. Examples of this scenario are found in the Cederberg and De Hoop areas where activities promoting the spread of IAPs are limited but where the capacity to deal with IAPs is reduced. There are, however, still opportunities to improve the situation thanks to the assertiveness of the managers currently in charge of the areas. They need to increase the management capacity (mainly by increasing the budget available) and the efficiency of prevention systems (i.e., early detection and clearing of initial focus)

Meltdown: Opportunities to bring IAPs under control decline as ongoing and expanding human activities promote their spread and the capacity of institutions to cope with invasions is poor. Examples of areas with such circumstances can be found in the Knysna and Kleinriver areas. Besides their resemblances, the overwhelming presence of invasive species in each area is attributable to different factors. Knysna has the appropriate institutional capacity (in terms of data and skilled people) to control IAPs, but funding does not match the magnitude of the problem. For Kleinriver, poor coordination among agencies and the lack of compliance from stakeholders in charge of clearing operations seem to be the primary factors thwarting effective management. Numerous human activities that promote the establishment and spread of invasive alien species are a problem in both areas. The problem is so immense that increasing the funding would not be enough to control the spread of IAPs; it is imperative to increase both management capacity and stewardship from private landowners and forestry companies

Losing ground: The impact of human activities in promoting the spread of IAPs is high, but agencies in charge of clearing operations have the appropriate capacity to contain invasions. The extent of IAPs increases gradually, but effective clearing operations prevent the system from degenerating into the Meltdown scenario. Clearing agencies, however, need to prioritize areas for clearing and allocate their resources appropriately to find an optimal situation where they only need to "Maintain the gains". Examples of this situation can be found at Assegaaibos and Berg River. These areas have the appropriate capacity to drive conditions toward "Maintain the gains" with additional funding, but need to maintain their current capacity over time and stimulate the implication of private landowners into clearing operations to prevent the situation degenerating toward "Meltdown"

Maintain the gains: This scenario is nirvana for all managers working on alien clearing, where both the management capacity and the activities that promote the spread of IAPs permit effective and sustainable control of the invasion. An example of this situation is the Cape Peninsula, where the funding received by Table Mountain National Park to control IAPs and the capacity of the agency in charge of the clearing (both in terms of data availability and in terms of clearing effectiveness on the ground) were adequate to substantially reduce the extent and abundance of IAPs. This situation is exceptional and not representative of the vast majority of areas within the CFR. Therefore, areas within this scenario need to not rely on their accomplishments and be aware of the importance of consolidating their current achievement.

Coordination among agencies and data consolidation are imperatives to assure the early detection of emergent foci of invaders from areas already free of aliens, and their maintenance over time

Scenarios are based on key uncertainties and their impacts on natural ecosystems (see Fig. 3a). Examples of areas (indicated in Fig. 1) for each specific scenario are also introduced, and the directions to reach the preferred future ("Maintain the gains") based on their management capacity and pressure from human activities having an impact on the spread of IAPs highlighted (trajectories are shown in Fig. 3b)

capabilities differs among areas, generating a wide and contrasting range of conditions across the region. However, some general patterns can be distinguished.

Areas with high levels of human activities that exacerbate plant invasion tend to map in the "Meltdown" scenario, because of the role of humans in facilitating the spread of invasions and the difficulties of managing fragmented landscapes with multiple stakeholders and contrasting interests. In contrast, areas with a sustainable reliable management capacity tend to fall within the "Losing ground" scenario, and some of them can easily reach the optimal scenario of "Maintain the gains" with an additional source of funding. At the other end of the spectrum ("Treading water" scenario) are remote areas that, despite receiving relatively low pressure from human activities, low or non-existent capacity to manage the spread of invasive species leads to increasing invasions. Overall, it seems that areas closer to highly human-modified habitats present a high success rate in controlling the spread of IAPs than more remote areas. Problems with invasive species are less visible in remote areas and generate less pressure for attention from interest groups. Logistical problems, for example relating to access in remote localities, are another contributing factor. This bias in favor of areas with higher population density has major repercussions, since remote areas with high conservation value receive lower priority.

What we learn from these scenarios is that the characteristics of invasive species and the environment in which their spread are less important in explaining the current status of IAPs than human activities and management responses. The ecological processes determining invasions are similar across areas (and scenarios) but other driving forces that define elements of human influence turn out to be responsible for divergences in the status of IAPs within the CFR. Numerous political and operational constraints preclude the development of standard approaches, and the management of IAPs must be adapted to the conditions of each particular area. In general, these findings build upon previous experiences and suggest that improved management of plant invasions in the CFR could be achieved by: 


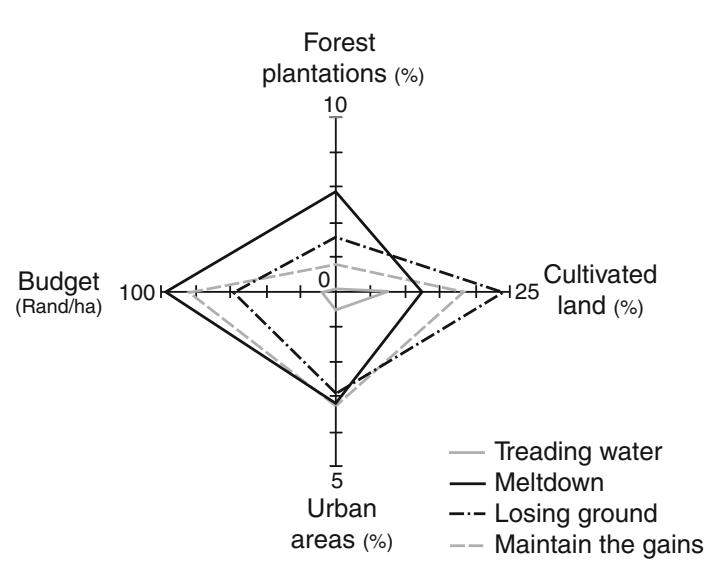

Fig. 4 Characterization of management scenarios for invasive alien plants in the Cape Floristic Region based on selected management projects representative of each scenario. Scenarios are presented in Box 1, and the localization of each management project within each scenario is presented in Fig. 3b. Scenarios were described based on four axes: 1 forest plantations ( $\%$ of the overall area), 2 cultivated land (\% of area), 3 urban area (\% of area) and 4 budget received in 2008 (Rand per hectare). These axes create a 4-dimensional space, where scores range from low (center) to high values (periphery). The polygons connecting the axes are just for visualization and indicate the mean value of the management projects included within each specific scenario

- Prioritizing management units throughout the whole CFR (van Wilgen et al. 2008), as well as to areas within those management units based on objective guidelines (Roura-Pascual et al. 2009);

- Improving awareness among the public and politicians of the situation regarding IAPs in the CFR and of the importance of the human influences in achieving the goals of biodiversity conservation and the sustainable delivery of ecosystems services (Boudjelas 2009);

- Working toward improved methods for IAP control on the ground, which consider the characteristics of the region (e.g., the feasibility of using prescribed burnings as part of an integrated control method) and/or assure the control of IAPs over a long-term period (e.g., through biological control; Macdonald 2004);

- Improving the implementation and enforcement of existing policies and legislation and assuring the compliance of various stakeholders (Shine et al. 2000);

- Increasing the budget available for management operations and guaranteeing the sustainability of funding over time (Leung et al. 2002);

- Motivating agencies in charge of clearing operations to develop strategic plans that consider preferred futures and unique drivers of invasion that operate in their area of control, to allow flexibility to accommodate unplanned eventualities, and to stimulate the development of skills of institutional and field workers (McNeely et al. 2001).
At lower levels of the decision-making process, circumstances and features of particular areas within the region create different bounds and sets of feasible options and interventions (Roura-Pascual et al. 2009). Various options exist to steer management initiatives toward preferred futures (Lodge et al. 2006). In general, however, options available for steering areas toward "Maintain the gains" at this level involve:

- Increasing levels of coordination between landowners and agencies in charge of clearing operations and also between agencies;

- Stimulating stewardship and commitment to prevailing legislation and policies;

- Improving the standard and accessibility of data on species distribution and disturbance regimes that affect the outcomes of management actions (such as seizing opportunities provided by wildfires to remove aliens at relatively low cost);

- Incorporating predictions of the spread of species and fire regimes to ensure cost-efficient management over the long term;

- Developing objective and transparent protocols for prioritizing areas for management attention considering both the current and likely future states of the environment;

- Improving the efficiency of management on the ground, by increasing the skills of field workers and managers and ensuring financial and logistical support over times appropriate for such management interventions (decades rather than years);

- Ensuring that already cleared areas remain free of IAPs (through regular follow-up operations), by maintaining the control effort over time and favoring early detection and clearing of initial foci.

Because of the inherent future uncertainties in both management capacity and changes in environmental conditions, and inherent differences among areas, strategies for the efficient management of IAPs in the CFR need to be, above all, dynamic and adaptable. However, it is important to indicate that political commitment and engagement from stakeholders (both landowners and agencies in charge of clearing operations) are ultimately responsible for improving the efficiency of management operations. It is only with the long-term engagement of the responsible parties that there is scope for bringing the extension of invasive species under control (Vitousek et al. 1997).

\section{Conclusions}

At a time of increasingly urgent debate on how best to manage "novel ecosystems", including those affected by 
invasive species (Hobbs et al. 2009), our study shows that scenario planning is useful for understanding the key drivers for invasion and for elaborating long-term control options, strategies and management interventions. Besides the benefits of making sense of the complexities involved in managing invasions, scenario planning stimulates discussion of future possibilities and facilitates the elaboration of solutions (Peterson et al. 2003). By applying scenario planning to our case study we were able to derive a framework, which revealed the importance of considering the multiple factors that facilitate the spread of invasions in different areas into a single, integrated management strategy. Strategies for controlling alien species cannot be formulated and implemented in isolation from the prevailing societal, political and legal realities. The establishment of an effective strategy for managing biological invasions requires the engagement of all the implicated parties-politicians, researchers, managers and civil society. The participation of all stakeholders is essential for shaping efficient strategies for controlling biological invasion and managing ecosystems supporting them.

Acknowledgments We thank G. G. Forsyth, D. C. Le Maitre and R. D. Zenni for help in disentangling the driving forces involved in the management of biological invasions, and R. Bailey, A. Brown, D. Kirkwood, D. Malan, G. Palmer, and A. Wannenburgh for help with positioning the management units on the scenario axes. The project was funded by the Global Environmental Facility (GEF) through the Cape Action for People and the Environment (CAPE) program. Financial support was also provided by the DST-NRF Centre of Excellence for Invasion Biology, the Catalan Agency for Management of University and Research Grants (Generalitat de Catalunya) through Beatriu de Pinós Postdoctoral Grants (2006 BP-A 10124 and 2008 BP-B 00042) to N. Roura-Pascual, and a grant from the Hans Sigrist Foundation to D. M. Richardson.

\section{References}

Apitz SE (2008) Adaptive management principles and sediment management: editorial: a call for discussions. J Soil Sediment $8: 359-362$

Berkhout F, Hertin J, Jordan A (2002) Socio-economic futures in climate change impact assessment: using scenarios as 'learning machines'. Global Environ Change 12:83-95

Biggs R, Simons H, Bakkenes M, Scholes RJ, Eickhout B, van Vuuren D, Alkemade R (2008) Scenarios of biodiversity loss in southern Africa in the 21st century. Global Environ Change 18:296-309

Bohensky EL, Reyers B, Van Jaarsveld AS (2006) Future ecosystem services in a Southern African river basin: a scenario planning approach to uncertainty. Conserv Biol 20:1051-1061

Boudjelas S (2009) Public participation in invasive species management. In: Clout MN, Williams PA (eds) Invasive species management. A handbook of principles and techniques. Oxford University Press, Oxford

Chapman RA, Le Maitre DC, Richardson DM (2001) Scenario planning: understanding and managing biological invasions in
South Africa. In: McNeely JA (ed) The great reshuffling: human dimensions of invasive alien species. IUCN, Gland, pp 195-208

Cowling RM, Pressey RL, Rouget M, Lombard AT (2003) A conservation plan for a global biodiversity hotspot-the Cape Floristic Region, South Africa. Biol Conserv 112:191-216

Fairbanks DHK, Thompson MW, Vink DE, Newby TS, van den Berg HM, Everard DA (2000) The South African land-cover characteristics database: a synopsis of the landscape. S Afr J Sci 96:6982

Higgins SI, Turpie JK, Costanza R, Cowling RM, Le Maitre DC, Marais C, Midgley GF (1997) An ecological economic simulation model of mountain fynbos ecosystems-dynamics, valuation and management. Ecol Econ 22:155-169

Hobbs RJ (2004) The working for water programme in South Africa: the science behind the success. Divers Distrib 10:501-503

Hobbs RJ, Arico S, Aronson J, Baron JS, Bridgewater P, Cramer VA, Epstein PR, Ewel JJ, Klink CA, Lugo AE, Norton D, Ojima D, Richardson DM, Sanderson EW, Valladares F, Vila M, Zamora R, Zobel M (2006) Novel ecosystems: theoretical and management aspects of the new ecological world order. Global Ecol Biogeogr 15:1-7

Hobbs RJ, Higgs E, Harris JA (2009) Novel ecosystems: implications for conservation and restoration. Trends Ecol Evol 24:599-605

Hulme PE (2003) Biological invasions: winning the science battles but losing the conservation war? Oryx 37:178-193

Hulme PE (2006) Beyond control: wider implications for the management of biological invasions. J Appl Ecol 43:835-847

Korte RF, Chermack TJ (2007) Changing organizational culture with scenario planning. Futures 39:645-656

Le Maitre DC, Richardson DM, Chapman RA (2004) Alien plant invasions in South Africa: driving forces and the human dimension. S Afr J Sci 100:103-112

Leung B, Lodge DM, Finnoff D, Shogren JF, Lewis MA, Lamberti G (2002) An ounce of prevention or a pound of cure: bioeconomic risk analysis of invasive species. Proc Roy Soc B Biol Sci 269:2407-2413

Lodge DM, Williams S, MacIsaac HJ, Hayes KR, Leung B, Reichard S, Mack RN, Moyle PB, Smith M, Andow DA, Carlton JT, McMichael A (2006) Biological invasions: recommendations for US policy and management. Ecol Appl 16:2035-2054

Macdonald IAW (2004) Recent research on alien plant invasions and their management in South Africa: a review of the inaugural research symposium of the working for water programme. S Afr J Sci 100:21-26

Mack MC, Simberloff D, Lonsdale WM, Evans H, Clout M, Bazzaz FA (2000) Biotic invasions: causes, epidemiology, global consequences, and control. Ecol Appl 10:689-710

McNeely JA, Mooney HA, Neville LE, Schei PJ, Waage JK (eds) (2001) Global strategy on invasive alien species. IUCN, Gland

Nel JL, Richardson DM, Rouget M, Mgidi TN, Mdzeke N, Le Maitre DC, van Wilgen BW, Schonegevel L, Henderson L, Neser S (2004) A proposed classification of invasive alien plant species in South Africa: towards prioritizing species and areas for management action. S Afr J Sci 100:53-64

Odada EO, Ochola WO, Olago DO (2009) Understanding future ecosystem changes in Lake Victoria basin using participatory local scenarios. Afr J Ecol 47:147-153

Peterson GD, Cumming GS, Carpenter SR (2003) Scenario planning: a tool for conservation in an uncertain world. Conserv Biol 17:358-366

Richardson DM, Macdonald IAW, Holmes PM, Cowling RM (1992) Plant and animal invasions. In: Cowling RM (ed) The ecology of fynbos. Nutrients, fire and diversity. Oxford University Press, Cape Town

Richardson DM, Moran VC, Le Maitre DC, Rouget M, Foxcroft LC (2004) Recent developments in the science and management of 
invasive alien plants: connecting the dots of research knowledge, and linking disciplinary boxes. S Afr J Sci 100:126-128

Roura-Pascual N, Richardson DM, Krug RM, Brown A, Chapman RA, Forsyth GG, Le Maitre DC, Robertson MP, Stafford L, van Wilgen BW, Wannenburgh A, Wessels N (2009) Ecology and management of alien plant invasions in South African fynbos: accommodating key complexities in objective decision making. Biol Conserv 142:1595-1604

Schwartz P (1991) The art of the long view: planning for the future in an uncertain world. Doubleday, New York

Seastedt TR, Hobbs RJ, Suding KN (2008) Management of novel ecosystems: are novel approaches required? Front Ecol Environ 6:547-553

Shine C, Williams N, Gündling L (2000) A guide to designing legal and institutional frameworks on alien invasive species. IUCN, Gland

Turpie JK, Heydenrych BJ, Lamberth SJ (2003) Economic value of terrestrial and marine biodiversity in the Cape Floristic Region: implications for defining effective and socially optimal conservation strategies. Biol Conserv 112:233-251

van Wilgen BW (2004) Scientific challenges in the field of invasive alien plant management. S Afr J Sci 100:19-20 van Wilgen BW, Bond W, Richardson DM (1992) Ecosystem management. In: Cowling RM (ed) The ecology of fynbos. Nutrients, fire and diversity. Oxford University Press, Cape Town, pp 345-371

van Wilgen BW, Le Maitre DC, Forsyth GG (2008) The prioritization of species and primary catchments for the purposes of guiding invasive alien plant control operations in the terrestrial biomes of South Africa. Council for Scientific and Industrial Research, Natural Resources and the Environment, Stellenbosch

Vitousek PM, D’Antonio CM, Loope LL, Rejmánek M, Westbrooks $R$ (1997) Introduced species: a significant component of humancaused global change. N Z J Ecol 21:1-16

Voinov A, Bromley L, Kirk E, Korchak A, Farley J, Moiseenko T, Krasovskaya T, Makarova Z, Megorski V, Selin V, Kharitonova G, Edson R (2004) Understanding human and ecosystem dynamics in the Kola Arctic: a participatory integrated study. Arctic 57:375-388

Weichselgartner J (2001) Disaster mitigation: the concept of vulnerability revisited. Disaster Prev Manage 10:85-95

Wilkenson L (1995) How to build scenarios. Planning for "long fuse, big bang" problems in an era of uncertainty. Wired (Special Edition, Scenarios: the future of the future), pp 74-81 


\title{
Erratum to: Managing biological invasions: charting courses to desirable futures in the Cape Floristic Region
}

\author{
Núria Roura-Pascual • David M. Richardson • \\ R. Arthur Chapman · Tanja Hichert • \\ Rainer M. Krug
}

Published online: 1 September 2010

(C) Springer-Verlag 2010

\section{Erratum to: Reg Environ Change \\ DOI 10.1007/s10113-010-0133-5}

The original version of this article unfortunately contained a mistake. In Fig. 2, the title of the $x$-axis should be "Uncertainty", not "Uncertainy".

The online version of the original article can be found under doi:10.1007/s10113-010-0133-5.

N. Roura-Pascual · D. M. Richardson · R. M. Krug

Centre for Invasion Biology, Department of Botany \& Zoology,

Stellenbosch University, Private Bag X1, Matieland 7602,

South Africa

e-mail: rich@sun.ac.za

R. M. Krug

e-mail: Rainer@krugs.de

R. Arthur Chapman

CSIR Natural Resources and the Environment,

P.O. Box 320, Stellenbosch 7599, South Africa

e-mail: arthur@oneworldgroup.co.za

R. Arthur Chapman

OneWorld Sustainable Investments, PO Box 8359,

Roggebaai 8012, South Africa

T. Hichert

Institute for Futures Research, Stellenbosch University,

P.O. Box 2010, Bellville 7535, South Africa

e-mail: Tanja@hichert.co.za

N. Roura-Pascual ( $₫)$

Àrea de Biodiversitat, Centre Tecnològic Forestal de Catalunya, Ctra. de St. Llorenç de Morunys km 2, 25280 Solsona, Catalonia

e-mail: nrourapascual@gmail.com 


\section{Supplementary material}

Online Resource 1 Certainties that set the pattern of events and make things happen in the management of invasive alien plants (IAPs) in the Cape Floristic Region, listed by category. The drivers plotted in Fig. 3a are indicated with an arrow $(\bullet)$.

\section{Political forces}

- Government departments are disconnected and sometimes produce policies with opposite effects on the spread of IAPs (e.g. policies that regulate the planting of alien trees, and those that regulate the management of invasive species).

- The awareness of the public, NGOs and politicians influences the success of management programs by increasing the funding available for clearing operations and/or limiting the introduction and spread of invasive species.

- The procedures driving the land reform (i.e. conversion of private properties into communal lands) are uncertain, and this uncertainty in future land ownership affects negatively the attitude of landowners in relation to the removal of IAPs from their properties.

\section{Social trends}

-Woody IAPs are used for poverty alleviation (fuelwood, building timber), which both reduces and promotes the extent of IAPs.

- The Working for Water is a public works program in which job creation is an important objective, so the allocation of resources is not always driven by environmental criteria.

- There is an ethical incentive to eradicate IAPs as more people become aware of their negative consequences

-Human activities (agriculture and food security, horticulture, forestry, biofuels, carbon sequestration) drive invasion by introducing new species and also transporting (intentionally or accidentally) already invasive species across the region.

- Fragmented landscapes with multiple landowners make the development of an integrated management strategy more complex, because of the multiple particular interests ("free-riders phenomenon").

\section{Economic realities}

- IAPs affect ecosystem services (flower harvesting, water production, etc) and reduce the opportunities to obtain economic benefits.

- IAPs reduce water production in a region already affected by water scarcity, with negative impacts on humans and natural ecosystems depending on it.

- There are economically sound reasons for controlling IAPs.

\section{Technological advances}

- Advances in methods for IAP control (e.g. biological control) can improve control, but advances in forestry practices can also favor the resistance of planted trees to biocontrol agents.

\section{Regulatory environment}

- Several legal instruments are available for driving IAP control initiatives through incentives, laws and compliance.

- The Conservation of Agricultural Resources Act (CARA) is in place to control the utilization of agricultural resources. It is currently the primary legal instrument that defines national strategies and management options for IAPs. 
- The National Environmental Management Biodiversity Act (NEMBA) aims to conserve the biodiversity of South Africa, and prohibits those species and activities that enhance the spread of IAPs.

\section{Environment interface}

- IAPs cause negative impacts on biodiversity and ecosystem functioning.

- Some degree of IAPs' spread is unpredictable, and requires management options to be flexible and adaptable.

- All areas in the CFR are susceptible to invasion in the absence of ongoing management intervention.

- Climate change (i.e., increase in $\mathrm{CO}_{2}$ concentrations and changed rainfall patterns) will impact more on native species than IAPs, which are better equipped to exploit changing conditions.

- Changes in land uses, disturbance and disaster events will intensify, making the region more vulnerable to the spread of IAPs.

\section{Management constraints}

- Management depends on multiple factors of different nature (not only environmental, but also socio-political), so management options need to be integrated across sectors.

- Funding is allocated annually and depends on fluctuating national priorities. Availability of fund is not always synchronized with biological realities, hampering the completion of long-term plans.

- The lack of accurate and up-to-date data on species distribution and fires, and their integration into a coordinate platform, precludes the development of appropriate control strategies.

- Follow-ups operations are crucial and are difficult to plan and implement due to complex issues relating to multiple landownership and fluctuating funding. - Landowners are responsible by law (although enforcement is weak) to clear IAPs on their properties. Willingness to cooperate and capacity need to be improved through education and empowerment.

- Institutional capacity (to plan management actions at regional and local scales) is inadequate, and improved skills and motivation are needed to decide/plan.

- Implementation capacity on the ground is also important, and skills are needed to do the clearing efficiently.

- Prioritization of areas for clearing cannot be done according to scientific/traditional planning (because of the job creation needs and the environmental variability).

- The extent and abundance of IAPs is immense in comparison with the resources available, and managers perceive the problem as one of "chasing a moving target". 
Online Resource 2 Uncertainties that influence the management of invasive alien plants (IAPs) in the Cape Floristic Region, listed by category.

\section{Management constraints}

1. How is funding (amount, regularity and reliability) going to change?

2. Is the political will, commitment to environmental principles (specifically in relation to the Working for Water programme) and willingness to commit resources to control activities going to change?

3. Is the institutional capacity (the incentive for people to become skilled) going to increase or decrease?

4. On the ground, will the effectiveness of clearing groups increase?

\section{Social trends}

5. Is the commitment and implementation from landowners going to make a difference in controlling the extent of IAPs?

6. How are human activities (compliance, introduction of new aliens, land use and property changes) going to influence the spread of IAPs?

\section{Regulatory environment}

7. Is the compliance to legislation (notably the Conservation of Agricultural Resources Act and the National Environmental Management: Biodiversity Act) going to make a difference in reducing the spread of IAPs? 
Online Resource 3 Box plots showing differences in distance to main decision centers, and percentage of urban areas, forest plantations and agricultural land between future scenarios for the management of IAPs. Numbers in the x-axis correspond to the management scenarios: Treading water (1), Meltdown (2), Losing ground (3) and Maintain the gains (4), described in Box 1. Boxes show 25\%-75\% of data and the median value (middle line), while whiskers the minimum and maximum values.
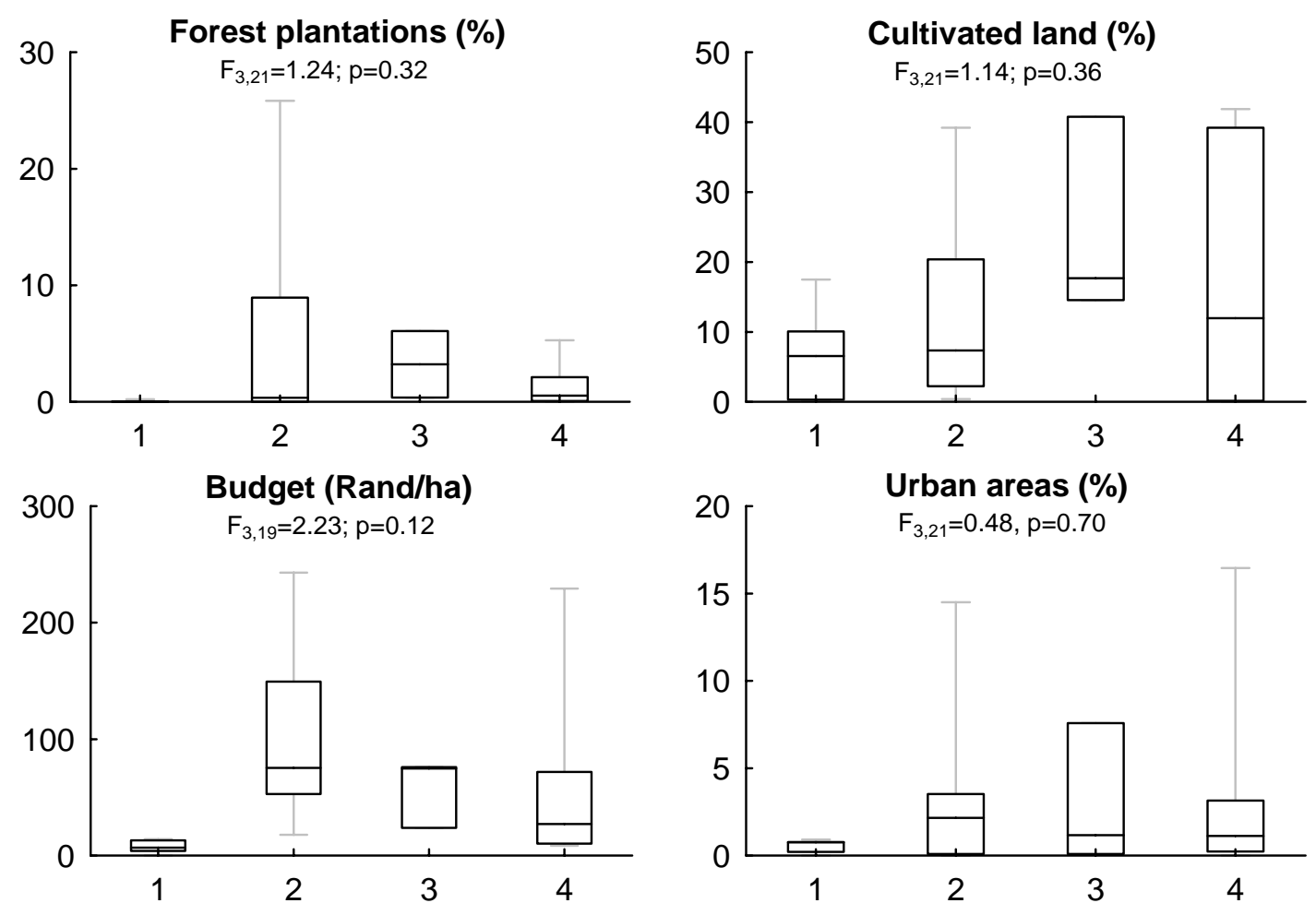